\title{
Worst case prediction of additives migration from polystyrene for food safety purposes: a model update.
}

\author{
Martinez Lopez, Brais; Gontard, Nathalie ; Peyron, Stephane
}

Published in:

Food Additives \& Contaminants: Part A - Chemistry, Analysis, Control, Exposure \& Risk Assessment

Link to article, DOI:

$10.1080 / 19440049.2017 .1402129$

Publication date:

2018

Document Version

Peer reviewed version

Link back to DTU Orbit

Citation (APA):

Martinez Lopez, B., Gontard, N., \& Peyron, S. (2018). Worst case prediction of additives migration from polystyrene for food safety purposes: a model update. Food Additives \& Contaminants: Part A - Chemistry, Analysis, Control, Exposure \& Risk Assessment, 35(3), 563-576.

https://doi.org/10.1080/19440049.2017.1402129

\section{General rights}

Copyright and moral rights for the publications made accessible in the public portal are retained by the authors and/or other copyright owners and it is a condition of accessing publications that users recognise and abide by the legal requirements associated with these rights.

- Users may download and print one copy of any publication from the public portal for the purpose of private study or research.

- You may not further distribute the material or use it for any profit-making activity or commercial gain

- You may freely distribute the URL identifying the publication in the public portal 


\section{Worst case prediction of additives migration from polystyrene for food safety purposes: a model update.}

\section{Brais Martínez López, Nathalie Gontard \& Stéphane Peyron}

To cite this article: Brais Martínez López, Nathalie Gontard \& Stéphane Peyron (2017): Worst case prediction of additives migration from polystyrene for food safety purposes: a model update., Food Additives \& Contaminants: Part A, DOI: 10.1080/19440049.2017.1402129

To link to this article: http://dx.doi.org/10.1080/19440049.2017.1402129

Accepted author version posted online: 07

Nov 2017.

Submit your article to this journal $\pi$

à

View related articles $\square$

View Crossmark data $\complement \pi$ 
Publisher: Taylor \& Francis \& Informa UK Limited, trading as Taylor \& Francis

Journal: Food Additives \& Contaminants: Part A

DOI: $10.1080 / 19440049.2017 .1402129$

\title{
Worst case prediction of additives migration from polystyrene for food safety purposes: an updated model.
}

\author{
Brais Martínez-López ${ }^{1}$, Nathalie Gontard ${ }^{2}$, Stéphane Peyron ${ }^{2}$ \\ ${ }^{1}$ National Food Institute, Food Production Engineering Research Group, Technical University of \\ Denmark,Søltofts Plads building 227. 2800 Kongens Lyngby, Denmark. \\ ${ }^{2}$ UMR IATE 1208, 2 Place Pierre Viala, 34060 Montpellier, France \\ bramar@food.dtu.dk
}

\begin{abstract}
A reliable prediction of migration levels of plastic additives into food requires a robust estimation of diffusivity. Predictive modelling of diffusivity as recommended by the EU commission is carried out using a semi-empirical equation that relies on two polymer-dependent parameters. These parameters were determined for the polymers most used by packaging industry (LLDPE, HDPE, PP, PET, PS, HIPS) from the diffusivity data available at that time. In the specific case of general purpose polystyrene, the diffusivity data published since then shows that the use of the equation with the original parameters results in systematic underestimation of diffusivity. The goal of this study was therefore, to propose an update of the aforementioned parameters for PS on the basis of up to date diffusivity data, so the equation can be used for a reasoned overestimation of diffusivity.
\end{abstract}

Keywords: diffusion in polymers, migration, modelling, polystyrene. 


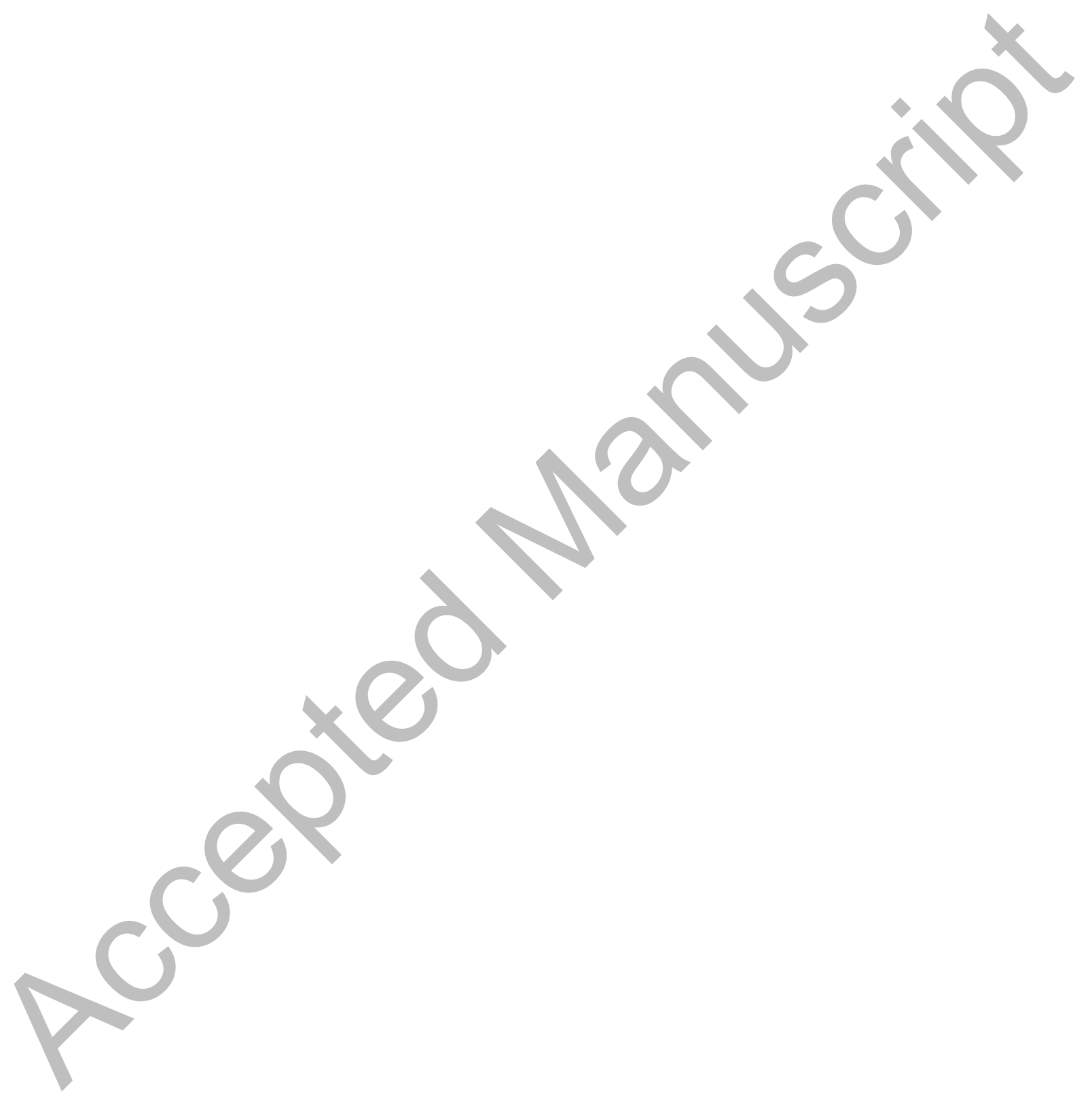




\section{Introduction}

Food contact materials (FCMs) must comply with EU regulation 1935/2004, which can be summed up in two main requirements: packaging materials shall not transfer their constituents to food in quantities that could (1) endanger the human health and (2) bring about deterioration in their organoleptic characteristics. To ensure the safety of consumers, EU regulation 10/2011 translates the requirements of the framework regulation $1935 / 2004$ to the specific case of plastic materials and lays down the procedure for their compliance. In addition to the requirement of inertness for plastic FCM's, regulation 10/2011 provides guidelines on the testing procedure for migration assessment. An important aspect of the regulatory framework is that it allows the use of "generally recognized diffusion models based on experimental data [...] under certain conditions" to determine overestimated migration levels of substances with the aim to prevent expensive and timeconsuming experiments. This way, the existing models describing migration are based on Fick's diffusion equation, which requires, additionally to the geometric and dimensional characteristics, two key parameters: $(1)$ the diffusion coefficient or diffusivity $(D)$, and (2) the partition coefficient $(K P L)$ for the two phases of the food/polymer system. A commonly accepted approach is the use of a $K P L$ value of 1 if the migrant is soluble in the food or 1000 otherwise (Hoekstra et al. 2015). In contrast to KPL, diffusivity must be determined for each polymer/migrant system in defined conditions (temperature, time), because it depends on physical characteristics of both, like molecular mass, volume, polarity of the diffusing molecule, and glassy or rubbery state of the polymer matrix. In addition to experimentation, $D$ can be determined via predictive modelling, which is generally based on empirical or semi-empirical relationships that predict diffusivity as a function of the steric hindrance of the diffusing molecule, often linked to its molecular weight and temperature as well as generic polymer-related parameters. One of the most widely used models for worst case prediction additives diffusion coefficient in the framework of food contact materials safety evaluation, is the Piringer model (Baner et al. 1996 Piringer 2007), also known as the Piringer Interaction model. This equation is recommended by the EU commission for the implementation of diffusion modelling and considered by the Food and Drug Administration as "a useful substitute for, or an addition to, experimental data under limited conditions" (FDA 2002). While not its original form, the model is given by Equation 1:

$$
D=e^{A_{p}^{\prime}-\frac{\tau}{T}-0.1351 M^{2 / 3}+0.003 M-\frac{10454}{T}}
$$

where $M$ is the molecular weight of the diffusing substance and $T$ is the temperature. As seen, this model relies on several constants, valid for any polymer/migrant system, as well as on two polymer-dependent parameters: $A_{p}^{\prime}$ and $\tau$. The recommended values of the parameters $A_{p}{ }^{\prime}$ and $\tau$, as well as the molecular weight and temperature ranges for their application are compiled in a practical guideline of the European Union (Simoneau 2010 and later Hoekstra et al. 2015), based on the migration data compiled by Begley et al. 2005. Since then, existing diffusivity data has been continuously expanded in scientific papers for various polymers and diffusing substances (Bernardo 2012, Bernardo et al. 2012, Bernardo 2013, Ogieglo et al. 2013). Among the common polymers employed for food packaging applications, polystyrene (PS), a petrochemical synthetic 
aromatic polymer made from the monomer styrene, for applications such as protective packaging (packing peanuts), containers (such as "clamshells"), lids, bottles, trays, tumblers, and disposable cutlery, has received little attention so far. The Piringer model is commonly recognized to be a trustworthy approach to determine overestimated values of additive diffusivity in polymers such as PE and PET, for which the large amount of available data allows derivation of reliable values of the parameters $A_{p}^{\prime}$ and $\tau$. Nevertheless, because of the scarce diffusivity data available for PS when its $A_{p}$ ' and $\tau$ parameters were established, the overestimation of diffusivity for PS based systems can appear uncertain. The goal of this work is to provide updated values for these parameters, based on literature review, in order to secure reasonably overestimated diffusion coefficients in PS. Piringer's parameters $A_{p}^{\prime}$ and $\tau$ were checked above and below glass transition temperature, against a large range of literature diffusivity data for different chemical substances in polystyrene. $A_{p}{ }^{\prime}$ and $\tau$ were then redefined to guarantee a sufficient overestimation degree to overcome eventual uncertainty of the literature data, for purposes of safety evaluation of the use of polystyrene as food contact material. Finally, in order to consolidate the update of Piringer's parameters, the migration levels resulting from the use of diffusion coefficients calculated with the new parameters, were compared to those resulting from the use of the experimental diffusivity data for each of the molecules.

Table 1: Characteristics of the Polystyrene diffusion coefficient datasets used in this work.

\section{Materials and methods}

\section{Diffusivity data}

A total of 183 diffusivity values in amorphous general purpose PS (with a glass transition temperature of 105 ${ }^{\circ} \mathrm{C}$ ) were collected from literature from 2000 to 2014: Bernardo 2012 (homologous series of linear alkanes, gravimetry), Bernardo 2013 (homologous series of linear alcohols, gravimetry), Bernardo et al. 2012 (homologous series of linear carboxylic acids, gravimetry and NMR), Ogieglo et al. 2013 (cyclohexane, spectroscopic ellipsometry), Dole et al. 2006 (toluene, chlorobenzene and phenyl-cyclohexane), Pinte et al. 2010 (homologous series of fluorescent tracers, FRAP), Tseng et al. 2000 (rubrene, FRAP), Martinez-Lopez et al. 2014 (p-terphenyl, Raman microspectroscopy and gas chromatography) Martinez-Lopez et al. 2016 (homologous series of oligophenyls and diphenyl-alkenes, Raman microspectroscopy). Diffusivity of styrene was deducted from migration data found at Begley et al. 2005. The main characteristics of these datasets are summarized in table1, and the actual 183 values of diffusivity have been made publicly available at the Zenodo repository, under the DOI: 10.5281/zenodo.883073

The same way, a total of 193 diffusivity values in polyethylene terephthalate (PET) were collected from the literature, spanning from 1999 to 2013: Launay et al. 1999 (water), Begley et al. 2004 (Tinuvin 234, 327 and 1577), Pennarun et al. 2004 (dimethylsulfoxide, toluene, phenol, 2,4-pentanedione, chlorobenzene, nonane, 1,1,1-trichloroethane, chlorooctane, phenylcyclohexane, ethyl hydrocinnamate, benzophenone, azobenzene and phenyl benzoate), Dole et al. 2006 (toluene, chlorobenzene, DMSO, phenyl-cyclohexane and benzophenone), Franz \& Welle 2008 (toluene, chlorobenzene and phenyl-cyclohexane), Welle \& Franz 2011 (Antimony), Welle \& Franz 2012 (acetaldehyde, benzene, THF), Ewender \& Welle 2013 (THF, Toluene, chlorobenzene, decane, phenyl-cyclohexane, dodecane, benzophenone, tetradecane, hexadecane, octadecane, eicosane, methyl stearate and docosane), and Haldimann et al. 2013 (antimony). Other data (Tinuvin 234, 571, 
Chimassorb 81, Irganox 1076, acetaldehyde, toluene, limonene, ethyl-butyrate, chloroform, citral, linalool, ethylene-glycol, methanol, ethanol, benzaldehyde, DMDS, tetracosane, methyl-dioxolane, m-xylene, Aterpineol and decane) were deducted from migration data found at Begley et al. 2005

These data have been regrouped into molecule families that share structural or physico-chemical characteristics in Figure 1. In the case of PS, regrouping was pretty straightforward, since many of the publications deal with only one molecule family. In the case of PET, most of the publications study groups of molecules that only have in common their technological value during PET fabrication, without sharing any structural characteristics. In an effort to make PET data comparable those of the PS the former has been regrouped this way: water, antimony, THF, dimethyl sulfides (dimethylsulfoxide and DMDS), organochlorides (chloroform, 1,1,1-trichloroethane, chlorooctane and lindane), alcohols (methanol, ethanol, ethylene-glycol, pentaerythriol, linalool), aldehydes (acetaldehyde, 2,4-pentanedione, citral), esters (ethyl hydrocinnamate, methyl stearate), linear alkanes (nonane, decane, dodecane, tetradecane, hexadecane, octadecane, eicosane, docosane, tetracosane), benzene derivatives (benzene, toluene, phenol, xylene, chlorobenzene, limonene, aterpineol), biphenyls (biphenyl, phenyl-cyclohexane, benzophenone, azobenzene, phenyl-benzanoate, Chimassorb 81), Tinuvins $(327,571,1577,234)$ and others (methyl-dioxolane, Irganox 1076).

\section{Calculation of Activation Energies}

Activation energies of diffusion were calculated by fitting the PS diffusivity data (see section: Diffusivity data) to a linearized version of equation 2 with the Matlab fit function (Mathworks, USA)

$$
D=D_{0} e^{\frac{-E a}{R T}}
$$

Where $D$ is the diffusion coefficient $\left(\mathrm{m}^{2} \mathrm{~s}^{-1}\right), \mathrm{D}_{0}$ is a pre-exponential factor $\left(\mathrm{m}^{2} \mathrm{~s}^{-1}\right), \mathrm{R}$ is the gas constant (8.31 J $\left.\mathrm{mol}^{-1} \mathrm{~K}^{-1}\right), \mathrm{T}$ is the temperature $(\mathrm{K})$ and Ea is the activation energy of diffusion $\left(\mathrm{J} \mathrm{mol}^{-1}\right)$

\section{Simulation of migration levels}

Migration levels in the foodstuff were calculated with equation 3.

$$
\frac{m_{F}}{A}=C_{0} \rho_{p} \frac{L}{100}\left(\frac{\alpha}{1+\alpha}\right) \sum_{n=1}^{\infty} \frac{2 \alpha(1+\alpha)}{1+\alpha+\alpha^{2} q_{n}^{2}} e^{\frac{-q_{n}^{2}}{L^{2}} D t}
$$

Where $\frac{m_{f}}{A}$ are the migration levels $\left(\mu \mathrm{g} \mathrm{dm}^{-2}\right), \mathrm{C}_{0}$ is the uniform initial concentration of migrant in the packaging ( $\mu \mathrm{g} \mathrm{g}^{-1}$ or $\left.\mathrm{ppm}\right), \rho_{\mathrm{p}}$ is the density of the polymeric material $\left(\mathrm{g} \mathrm{m}^{-3}\right), \mathrm{L}$ is the thickness of the packaging layer $(m), D$ is the effective diffusion coefficient of the migrant through the packaging material $\left(\mathrm{m}^{2} \mathrm{~s}^{-1}\right), \mathrm{t}$ is the time $(s), q_{n}$ is the $n^{\text {th }}$ root of the transcendental equation: 


$$
\tan q_{n}=-\alpha q_{n}
$$

And $\alpha$ is the ratio of volumes of food and packaging, weighted by the partition coefficient. Therefore:

$$
\alpha=\frac{1}{K_{P F}} \frac{V_{F}}{V_{p}}
$$

Equation 3 is a solution to Fick's second law for a mass transfer process completely dominated by diffusion. This equation is number 4.37 in Crank 1980, adapted as in Hoekstra et al. 2015 for the calculation of migration

levels in food. This way, the product $C_{0} \rho_{p} L A \frac{\alpha}{1+\alpha}$ the exact equivalent to the amount of migrant in food at equilibrium (usually called $m_{F, \infty}, m_{F, e q}$ or similar), and the factor 100 converts $\mathrm{m}^{2}$ into $\mathrm{dm}^{2}$.

In this work, the calculation of migration levels was done trying to simulate the conditions of a standard migration test for amorphous PS: $C_{0}=500 \mu \mathrm{g} \mathrm{g}^{-1}, \rho_{\mathrm{p}}=1.05 \cdot 10^{6} \mathrm{~g} \mathrm{~m}^{-3}, \mathrm{~L}=300 \cdot 10^{-6} \mathrm{~m}$. The packaging/food ratio was kept to $6 \mathrm{dm}^{2} \mathrm{~L}^{-1}$. Two values of $\alpha$ where used: 0.05 and 50 . With the considered packaging/food volume ratio, $\alpha=0.05$ corresponds to a partition coefficient of 1111 and represents a migrant that does not have much affinity for the foodstuff, while $\alpha=50$ corresponds to a partition coefficient of 1.11 , and represents a migrant that distributes nearly equally between the packaging and the foodstuff at equilibrium. The diffusion coefficient was taken from the literature data (see section: Diffusivity data), or calculated with equation 1, while the roots of the transcendental equation 4 were calculated with the fzero function of Matlab 2015a.

\section{Estimation of $A_{p}^{\prime}$ and $\tau$ for overestimating purposes}

The parameters $A_{p}^{\prime}$ and $\tau$ from equation 1 were estimated by minimizing the sum of the square residuals between the predictions and the experimental diffusion coefficients multiplied by a nominal overestimating factor of $\times 25$, as expressed by equation 6 . The minimization algorithm was based on the Levenberg-Marquardt algorithm, an optimization routine predefined in Matlab 2015a.

$$
\operatorname{SSQR}=\sum_{i=1}^{n}\left(D_{\text {pred }, i}-25 D_{\text {exp }, i}\right)^{2}
$$

\section{Calculation of overestimation of migration levels}

The overestimation of the migration levels was calculated with the ratio $\frac{m_{F, \text { pred }}}{m_{F, \text { exp }}}$, where $m_{F, \text { pred }}$ are the migration levels calculated with equation 3, making use of the diffusion coefficients predicted with equation 1 and the new parameters displayed in Table 2 , and $m_{F, \text { exp }}$ are the migration levels, also calculated with equation 3 , but making use of the diffusivity found in literature instead (see section: Diffusivity data). 


\section{Results.}

\section{Applicability of the current overestimating model to the existing literature data.}

Figure 1 shows the diffusivity data (scatter) gathered from literature for PET (a) and PS (b), as well as the diffusivity predicted by equation 1 using the original parameters $A_{p}^{\prime}$ and $\tau$ found at (Hoekstra et al. 2015) (continuous lines). As it can be seen, while the diffusivity data covers a similar temperature range for both polymers $(20-180 \stackrel{\circ}{\circ})$, the molecular weight range is significantly different: PET diffusivity data lays within 0 to $600 \mathrm{~g} \cdot \mathrm{mol}^{-1}$, while amorphous PS goes from 0 to $1200 \mathrm{~g} \cdot \mathrm{mol}^{-1}$. The data lays within different, but yet comparable ranges for each of the polymers, spanning $10^{-22}-10^{-8} \mathrm{~m}^{2} \mathrm{~s}^{-1}$ for PET and $10^{-20}-10^{-10} \mathrm{~m}^{2} \mathrm{~s}^{-1}$ for PS, with the fastest molecules lying approximately within the interval $0-250 \mathrm{~g} \mathrm{~mol}^{-1}$ for PS.

The relationship between diffusivity with molecular weight is different for each of the polymers. Regarding the projection of $D$ values measured at the same temperature in the PET, the diffusion coefficient does not seem to be linked to the unique influence of the molecular weight of the diffusing molecules and was probably impacted by other molecular characteristics. For PS, the dependence of $D$ on $M$ appears to follow two differentiated patterns. Within the interval $0-230 \mathrm{~g} \mathrm{~mol}^{-1}$, diffusivity decreases from $10^{-10}$ to $10^{-19} \mathrm{~m}^{2} \mathrm{~s}^{-1}$ in a approximately exponential way for each temperature and molecule family. Similarly, within the molecular weight interval 230 - $1200 \mathrm{~g} \mathrm{~mol}^{-1}$, diffusivity goes from $10^{-10}$ to $10^{-19} \mathrm{~m}^{2} \mathrm{~s}^{-1}$, in a decreasing exponential way along with molecular weight, for each temperature and molecule family. Nevertheless, as the molecular weight interval is significantly larger in this second interval, (spanning 970 instead of $230 \mathrm{~g} \mathrm{~mol}^{-1}$ ), the diffusivity decrease is much more slight than in the $0-230 \mathrm{~g} \mathrm{~mol}^{-1}$ interval. It should be pointed out that if the molecular weight region $0-600 \mathrm{~g} \mathrm{~mol}^{-1}$ of the PS was zoomed in to make it comparable to the whole molecular weight interval studied for PET, this distinction at $230 \mathrm{~g} \mathrm{~mol}^{-1}$ would be far less clear or even indistinguishable.

The diffusivity seems to be linked to the temperature by means of the activation energy, as expressed by the Arrhenius relationship (equation 2). This holds true for virtually any molecule tested on PET, for both the glassy and the rubbery state, showing activation energy values that go from 3 to $310 \mathrm{~kJ} \mathrm{~mol}^{-1}$ on the molecular weight interval between 20 to $194 \mathrm{~g} \mathrm{~mol}^{-1}$ (Welle 2013). As shown in Figure 2, PS shows activation energy values that are comparably lower, and go from 58.6 to $316 \mathrm{~kJ} \mathrm{~mol}^{-1}$, for a molecular weight interval between $46-1120 \mathrm{~g}$ $\mathrm{mol}^{-1}$.

The continuous lines in Figure 1 represent the predictions resulting from the use of equation 1 with the original parameters proposed at (Hoekstra et al. 2015). According to the published purpose of the equation, these predictions should overestimate diffusivity for any molecular weight or temperature. In reality, the achieved overestimation is very different for PET and for PS. For PET (Figure 1a), the use of the equation with the original parameters results in systematic overestimation of diffusivity at any molecular weight and temperature with very few exceptions: water $\left(18 \mathrm{~g} \cdot \mathrm{mol}^{-1}\right)$ whose diffusion coefficient is underestimated by several orders of magnitude; as well as some aldehydes of around $50 \mathrm{~g} \cdot \mathrm{mol}^{-1}$, whose diffusion coefficients are underestimated by one order of magnitude at worst. In contrast, Figure $1 \mathrm{~b}$ shows a very different predicting scenario for PS, for which the under or overestimation of diffusivity seems to be strongly related to the temperature and molecular weight of the migrant. This way, the resulting under/overestimation is well differentiated for molecules below and above $230 \mathrm{~g} \cdot \mathrm{mol}^{-1}$, as well as above and below the glass transition temperature of 105 oC. This means that unfortunately, the predictions of the equation may be several orders of magnitude above or below the experimental diffusivity value. Summarizing, while the use of the equation with the original 
parameters overestimates diffusivity in a fairly satisfactory way for PET, it cannot be relied upon for PS for safety aspects. The reader should be reminded that the recommendations from Hoekstra et al. 2015, specify two sets of $A_{p}^{\prime}$ and $\tau$ parameters to be used with equation 1 for the PET: one for below and one for above the glass transition temperature of $70 \stackrel{\circ}{ } \mathrm{C}$, but only one for the PS, for temperatures below $70 \stackrel{\circ}{ }$, and a molecular weight of $104-647 \mathrm{~g} \mathrm{~mol}^{-1}$.

Two conclusions can be drawn from these analysis: first, the $A_{p}^{\prime}$ and $\tau$ parameters for PS may have been found to yield reliable estimations of diffusivity, according to the existing literature data when they were first determined by (Begley et al. 2005), but can be considered obsolete according to the diffusivity data available for PS today. Second, due to the large molecular weight interval covered by these experimental diffusivity data (twice as large as for PET), as well as the complex dependence of diffusivity with molecular weight and temperature, it seems unrealistic expecting to obtain reliable predictions (overestimates or not), by using equation 1 with just one set of parameters. Consequently, it seems advisable to split the $M$ and $T$ space according to the previously identified dependences: above and below $230 \mathrm{~g} \mathrm{~mol}^{-1}$, and above and below the glass transition temperature $(105 \stackrel{\circ}{\circ})$, resulting in a total of four $M, T$ regions, that from now on will be named as:

- Region a: $M<230 \mathrm{~g} \cdot \mathrm{mol}^{-1}, T<T_{g}$

- Region b: $M<230 \mathrm{~g} \cdot \mathrm{mol}^{-1}, T>T_{g}$.

- Region c: $M>230 \mathrm{~g} \cdot \mathrm{mol}^{-1}, T<T_{g}$.

- Region d: $M<230 \mathrm{~g} \cdot \mathrm{mol}^{-1}, T>T_{g}$.

The median and average of the experimental diffusivities, as well as the amount of experimental values for each region can be seen in Table 2. With this division of the $M, T$ space in mind, it is much easier to identify typical diffusivity values, and hence to set a realistic overestimating factor for the diffusion coefficient and see its impact on the calculation of the migration levels.

Figure 2: Activation energies of diffusion in function of the molecular weight for the molecules displayed in Figure $1 b$.

\section{Dimensioning an overestimating factor}

As said, the published purpose of equation 1 is to compute overestimated diffusion coefficients for a migrant of

Figure 1: Experimental diffusivity data (scatter), and predictions of equation 1 at 35, 50, 65, 75, 105, 125 and 150 ㅇ $\mathrm{C}$ with the original parameters found at Hoekstra et al. 2015 for PET (a) and amorphous PS (b). The coloured bar represents the temperature in celsius. Table 1 displays the main characteristics of the PS datasets. 
a given molecular weight, for a particular polymer at a specific temperature. The use of these overestimated diffusivities in equation 3 results therefore in overestimated migration levels of that migrant into food, that can be used as a worst-case scenario for safety purposes. While worst case scenarios are a classic safety approach, the use of equation 1 for amorphous PS is hindered by the lack of guidelines about i) what is the current overestimating factor that can be expected from equation 1 , with respect to experimental diffusivities, and ii) what is the influence of a given degree of overestimation of diffusivity on the prediction of migration levels. Consequently, the application of equation 1 for safety purposes, requires setting an acceptable and realistic overestimating factor for the diffusion coefficient. Moreover, this factor should be based on its effect on the prediction of migration levels.

Figure 3 represents the evolution of the migration levels in food computed with equation 3 , using the conditions detailed in the section on Simulation of migration levels, for a partition coefficient of 1.11 for each of the four $\mathrm{M}, \mathrm{T}$ regions. As said, under these conditions, this corresponds to a value of $\alpha=50$, or a migration limit (equilibrium value or solubility limit) of $1541 \mu \mathrm{g} \mathrm{dm}^{-2}$. In order to illustrate the migration kinetics for each of the regions, as well as the influence of a potential over/underestimation of the diffusion coefficient, the simulation was carried out with three different diffusion coefficients:

- The median diffusivity of each of the regions.

- The median multiplied by a factor $\times 10$.

- The median multiplied by a factor $\times 25$.

The medians represent not only the central values of each of the regions, but also typical diffusivity values found for amorphous polystyrene. These typical values can be used as a basis to extract general rules about how a certain degree of overestimation affects the prediction of the migration levels. From lowest to highest the medians are, in $\mathrm{m}^{2} \mathrm{~s}^{-1}: 8.2910^{-18}$ (region c), $8.410^{-15}$ (region d), $810^{-13}$ (region a) and $110^{-11}$ (region b). As would be expected, because of the significantly different diffusion coefficients, migration kinetics are different for each $M, T$ region. Surprisingly, due to the low migration limit $\left(1541 \mu \mathrm{g} \mathrm{dm}{ }^{-2}\right)$ imposed by the low value of $\alpha$, and the short migration time (10 days), the overestimating factor does not have such a great influence as it could have been expected. Region a reaches a practical equilibrium after 2.5 days with the median diffusion coefficient, after $7.2 \mathrm{~h}$ with the overestimating factor of $\times 10$, and after $2.4 \mathrm{~h}$ with the overestimating factor of $\times 25$. The median diffusion coefficient of region $b$ is not only the highest of the four regions, but high in general terms. This way, equilibrium is reached within the first $3 \mathrm{~h}$ for the median diffusivity value, and within the first hour for both the $\times 10$ or the $\times 25$ overestimating factors; rendering the overestimating factors virtually useless under these conditions. Region c is significantly different. After 10 days, the migration levels are below $10 \mu \mathrm{gm}^{-2}$ (less than $1 \%$ of the equilibrium value) using the median diffusivity, around $29 \mathrm{\mu g} \mathrm{dm}^{-2}$ (around $2.1 \%$ of the equilibrium value) for the $\times 10$ factor, and of $45 \mu \mathrm{g} \mathrm{dm}^{-2}$ (3.2\% of the equilibrium value) for the $\times 25$ factor. In other words, after 10 days, an overestimation of diffusivity of $\times 10$ results on a $\times 2.9$ overestimation of the migration levels, while an overestimation of diffusivity of $\times 25$ results on an overestimation of the migration levels of $\times 4.5$. Regarding region $d$, after 10 days, the migration levels are $454 \mathrm{\mu g} \mathrm{dm}^{-2}$ (around a 30\% of the equilibrium value) using the median diffusivity, around $1250 \mathrm{\mu g} \mathrm{dm}^{-2}$ (around $90 \%$ of the equilibrium value) for the $\times 10$ factor, and the equilibrium value for the $\times 25$ factor. In other words, after 10 days, an overestimation of diffusivity of $\times 10$ results on a $\times 2.8$ overestimation of the migration levels, while an overestimation of diffusivity of $\times 25$ results on an overestimation of the migration levels of $\times 3.1$. To summarise, overestimating the diffusion coefficient more than $\times 10$ has no significant influence on the 
Figure 3: Evolution of the migration levels calculated with equation 3, for each of the M,T regions over 10 days, $\left(\alpha=50, C_{0}=500 \mathrm{ppm}, \mathrm{L}=300 \mu \mathrm{m}\right.$ and $6 \mathrm{dm}^{2}$ plastic $\left.L_{\text {food }}{ }^{-1}\right):$ a) region $\left.\mathrm{a}: \mathrm{M}<230 \mathrm{~g} \mathrm{~mol}^{-1}, \mathrm{~T}<\mathrm{Tg}, \mathrm{b}\right)$ region b: $\mathrm{M}<230 \mathrm{~g} \mathrm{~mol}^{-1}, \mathrm{~T}>\mathrm{Tg}, \mathrm{c}$ ) region $\mathrm{c}: \mathrm{M}>230 \mathrm{~g} \mathrm{~mol}^{-1}, \mathrm{~T}<\mathrm{Tg}$ and d) region d $\mathrm{M}>230 \mathrm{gmol}^{-1}, \mathrm{~T}>\mathrm{Tg}$. Migration levels were calculated for three different diffusivity values: the median of the diffusivities of each region (black line), the median of the multiplied by a 10 factor (dark brown) and the median of the region multiplied by a factor 25 (light brown).

migration levels for either regions $a$ or $b$, while overestimating the diffusion coefficient of $\times 25$ yields a reasonable overestimation of the migration levels for regions $c$ and $d$. As these calculations have been carried out under the assumption that all the migrants are equally soluble in the polymer and the food, it can be concluded that setting an overestimating factor of $\times 25$ for every region results in reasonable overestimation of the migration levels for safety purposes.

\section{Calculating parameters for nominal overestimation of the diffusion coefficient}

As stated previously (see section: Estimation of $A_{p}^{\prime}$ and $\tau$ for overestimating purposes), an overestimation of diffusivity of $\times 10$ and $\times 25$ is enough in most of the cases for migrants belonging to regions $a$ and $b$, and $c$ and $d$ respectively. In order to readjust the equation to these new predicting requirements, it appears necessary to re-dimension the parameters $A_{p}{ }^{\prime}$ and $\tau$. As explained in the section on Estimation of $A_{p}{ }^{\prime}$ and $\tau$ for overestimating purposes, this is achieved by multiplying the experimental diffusivity data by the desired nominal overestimation factor previously to the parameter fitting. Nevertheless, because of the wide range of diffusivity values, and the complex dependence of diffusivity on the molecular weight and temperature, especially in regions $a$ and $b$, the imposition of a nominal estimation to the experimental values does not necessarily guarantee, in the practice, that exact degree of overestimation for every single case. In order to avoid undesired underestimation, and to simplify the practical use of equation 1 , four new sets of parameters $A_{p}^{\prime}$ and $\tau$ were dimensioned for a nominal overestimation factor of $\times 25$ over the experimental diffusivity data of each region.

Figure 4 represents the same experimental diffusivity data (scatter) represented in Figure $1 \mathrm{~b}$. Here, the predictions of equation 1 have been updated by using the parameters calculated for the nominal overestimation of $\times 25$ that are displayed in Table 2 . As it can be seen, with very few exceptions, the predictions of the diffusion coefficient, represented by the continuous lines lay above the experimental data at the same temperature, hence overestimating the diffusion coefficient. The effect of this overestimation on the migration levels can be seen in Figure 5, which compares the migration levels computed with equation 3 using the experimental diffusivity data, with the migration levels computed with the diffusivity predicted by equation 1 after 10 days for $\alpha=50$, using the original parameters $A_{p}^{\prime}$ and $\tau$ (Figure 5a), and those calculated for a nominal overestimation of $\times 25$ (Figure $5 b$ ). As was suggested (see section on Dimensioning an overestimating factor), many molecules belonging to region $a$, as well as the practical totality of migrants belonging to region $b$ have reached equilibrium after 10 days, and probably already have after a few hours or days of plastic/food contact. These migrants can be easily identified because their migration levels (either experimental or predicted) correspond to the migration limit for the studied case: $1541 \mu \mathrm{g} \mathrm{dm}{ }^{-2}$. It should be pointed out that most of 
these data were determined by Bernardo (Bernardo 2012, Bernardo et al. 2012, Bernardo 2013), and present extremely high diffusion coefficients. As we have speculated (Martinez-Lopez et al. 2014), this may be due to an underestimation of their solubility limit, or to the plasticization of PS. Nevertheless, as they represent a significant portion of the data, they should be taken into account for safety purposes.

Table 2: Values of $A_{p}^{\prime}$ and $\tau$ calculated from the fit for a nominal overestimation of $\times 25$ in every region. The column $n$ designs the number of diffusivity values used for each determination.

Figure 4: plot of literature diffusivity data for PS (scatter) and prediction from equation (1) by using the parameters shown in Table 2, which have been determined for a nominal overestimation of $\times 25$. Symbols represent the same molecule families as in figure $1 b$.

Figure 5: Prediction of migration levels $\mu \mathrm{g} \mathrm{dm}-{ }^{2}$ after 10 days and $\alpha=50$, by using equation 2 with the experimental data gathered for amorphous PS (scatter), as well as the diffusivity values predicted by equation 1 with the original parameters found at Hoekstra et al. 2015 (a), and the parameters found for a nominal overestimation of the diffusion coefficient of $\times 25$, that can be found in Table 2(b). Symbols represent the same molecule families as in figure $1 \mathrm{~b}$.

\section{Assessment of the actual overestimation of the migration levels}

Although both Figure 4 and Figure 5 picture a scenario in which underestimation of either $\mathrm{D}$ or the migration levels does not apparently occur, more comprehensive verification is required. This has been carried out by individual comparison of the migration levels predicted by using the diffusion coefficients for a nominal overestimation of $\times 25\left(m_{F, \text { pred }}\right)$, and the ones predicted by using the experimental diffusion coefficients $\left(m_{F, \text { exp }}\right)$. Figure 6 depicts the over/underestimation of the migration levels for each individual molecule, understood as the $\frac{m_{F, \text { pred }}}{m_{F, \exp }}$ ratio. This way, underestimation of the migration levels can be understood as a $\frac{m_{F, \text { pred }}}{m_{F, \exp }}$ below 1 , and overestimation as a $\frac{m_{F, \text { pred }}}{m_{F, \exp }}$ ratio above 1. Four cases have been considered: Figure 6a: original parameters and $\alpha=0.05$, Figure $6 \mathrm{~b}$ : parameters calculated for a nominal overestimation of $\times 25$ and $\alpha=0.05$, Figure $6 \mathrm{c}$ : original parameters and $\alpha=50$, and Figure $6 \mathrm{~d}$ : parameters calculated for a nominal overestimation of $\times 25$ and $\alpha=50$. The rest of the conditions are as specified in the section)Simulation of migration levels; $C_{0}=500 \mu \mathrm{g} \mathrm{g}^{-1}$, $\rho_{\mathrm{p}}=1.0510^{6} \mathrm{~g} \mathrm{~m}^{-3} \mathrm{~L}=300 \times 10^{-6} \mathrm{~m}, \mathrm{C}_{0}=500 \mu \mathrm{g} \mathrm{g}^{-1}, \rho_{\mathrm{p}}=0.95 \times 10^{6} \mathrm{~g} \mathrm{~m}^{-3}, \mathrm{~L}=300 \times 10^{-6} \mathrm{~m}$. The packaging $/$ food ratio was kept to $6 \mathrm{dm}^{2} \mathrm{~L}^{-1}$ with 10 days of contact. 
If only the case of $\alpha=0.05$ was considered (Figure $6 a$ and $b$ ), it might appear that the calculation of the diffusion coefficient by equation 1 with the original parameters (Figure 6a) only leads to underestimation for a few molecules belonging to region a, mostly carboxylic acids, linear alkanes and linear alcohols; as well as some fluorescent tracers way above the glass transition temperature, belonging to region $\mathrm{d}$. If the parameters from Table 2 are used instead, it appears that underestimation of the migration levels does not occur in any case. Nevertheless, this apparent safety is a result of the use of $\alpha=0.05$, which as previously mentioned, actually corresponds to a partition coefficient of 1111 , which translates into a maximum concentration of $67.9 \mu \mathrm{g} \mathrm{dm}$ under these conditions. This migration limit is so low, that even very slow molecules, such as those from region c can reach it within the first 10 days, hence the great amount of molecules showing a $\frac{m_{F, p r e d}}{m_{F, \exp }}$ of 1 . It may very well be the case that underestimation would have shown if the simulations that are shown in either Figure 6a or $b$ were made for a time shorter than 10 days, but in the authors opinion, this would not have any practical consequences. 
Figure 6: Overestimation of migration levels computed with equation 1 after 10 days, calculated as the ratio between the migration levels resulting from the use the diffusivity data predicted by equation 1 ( $\mathrm{M}_{\mathrm{F}, \text { pred }}$ ) and the experimental diffusivity data found in literature $\left(M_{F, e x p}\right)$. (a) original parameters and $\alpha=0.05$, (b) parameters from Table 2 and $\alpha=0.05$, (c) original parameters and $\alpha=50$, (d) parameters from Table 2 and $\alpha=50$.

Consequently, the case of $\alpha=50$ (Figure $6 c$ and $d$ ) is presented as much more representative of a worst-case scenario. Again, $\alpha=50$ corresponds under these conditions to a partition coefficient of 1.11 and a migration limit of $1541 \mathrm{\mu g} \mathrm{dm}^{-2}$, with the migrant nearly equally distributed between the polymer and the foodstuff at equilibrium. Only molecules with high diffusion coefficients can reach such a high migration limit within 10 days. As anticipated in Figure 1b, the original parameters underestimate the diffusion coefficient by several orders of magnitude. Accordingly, Figure $6 c$ shows underestimation of the migration levels for almost every linear alkane, linear alcohol and carboxylic acid belonging to regions $a$ and $b$, some of the oligophenyls and the diphenyl alkenes, many fluorescent tracers above $135{ }^{\circ} \mathrm{C}$, as well as rubrene above $125{ }^{\circ} \mathrm{C}$ (region d). On the other hand, Figure $6 \mathrm{~d}$ shows that calculation of the migration levels making use of the diffusion coefficients predicted with the overestimating parameters from Table 2, solves the underestimation issue to a large extent. There are still some exceptions, such as the carboxylic acid of $116 \mathrm{~g} \mathrm{~mol}-1$ at 35 and $45{ }^{\circ} \mathrm{C}$ (region a), the carboxylic acid of $256 \mathrm{~g} \mathrm{~mol}-1$ at the glass transition temperature of $105^{\circ} \mathrm{C}$, as well as the linear alcohols of 242 $\mathrm{g} \mathrm{mol}^{-1}$ at 95 and $105{ }^{\circ} \mathrm{C}$ (regions $\mathrm{c}$ and d). These molecules exhibit diffusion coefficients that are significantly above what would have been expected at such temperatures (above $10-12 \mathrm{~m}^{2} \mathrm{~s}^{-1}$ ). Unfortunately, solving the underestimating issue comes at the cost of overestimating the migration levels, which can reach $\times 200$ or more in some cases. This, as well as the few underestimating cases mentioned above may be addressed by dividing the $M, T$ space into more regions, or by increasing the nominal overestimating factor of the diffusion coefficient for the current regions where these molecules lie. Further division of the M,T space would result in extra sets of parameters: from four to at least 6 sets. Of course, one can propose an unlimited number of sets of parameters (up to one per molecule), but this would go against the general idea behind the equation, and would seriously hinder its practical applicability. On the other hand, if the few underestimating exceptions were addressed by increasing the nominal overestimating factor of the whole region, a factor of at least $\times 120$ would probably be required; and this would lead to yet more unrealistic overestimation of the migration levels of the other molecules. Since the exceptions are so few, and as the calculations have been made with a fairly worst case scenario partition coefficient, the authors' opinion is that the current division of the M,T space and the current nominal overestimating factor of $\times 25$ offer a good compromise between safety and applicability, taking into account the difficulty of building a general model to estimate diffusivity for such a large set of molecules. Of course, the publication of new diffusivity or partition data for amorphous PS in the literature should lead to revision of the parameters proposed in this work. 


\section{Physical meaning of $A_{p}^{\prime}$ and $\tau$.}

The main use of equation 1 is, as said, the overestimation of diffusion coefficients for safety purposes. Nevertheless, the original determination procedure for $A_{p}{ }^{\prime}$ and $\tau$ described by Begley et al. 2005 attributes them some physical meaning. This physical meaning is probably based on the mechanistic origins of the equation as a way to calculate diffusion coefficients of $n$-alkanes in polyethylene. For example, in Piringer 2007, it is stated that the factor 0.1351 can be used as an acceptable approximation for most hydrocarbons and other solutes with low polarity. Equation 1 is, apparently, a generalization of the case of $n$-alkanes in polyethylene to plastics, in which the diffusing substances are exclusively represented by their molecular weight $M$. As already stated, $A_{p}^{\prime}$ together with $\tau$ are assumed to be the polymer-dependent parameters.

The parameter $\tau$, together with the constant 10454, both with the formal dimension of temperature, are supposed to contribute to the activation energy of diffusion, according to equation 7 (Begley et al. 2005).

$$
E_{A}=(10454+\tau) R
$$

where $R=8.3145 \mathrm{~J} \mathrm{~mol}^{-1} \mathrm{~K}^{-1}$ is the gas constant. According to this approach, it is possible to describe all polymers and diffusing substances with only two values of $\tau$, which are calculated on the basis of activation energy data of a large series of migrants from literature, and aim at simplifying the contribution of activation energy (Mercea 2007). The values are $\tau=O \mathrm{~K}$, corresponding to a mean $E_{A}=87 \mathrm{~kJ} \mathrm{~mol}^{-1}$ for presumed lowbarrier polymers that allow fast diffusion: LDPE, rubber PP, PS, HIPS and PA; and $\tau=1577 \mathrm{~K}$, corresponding to a mean $E_{A}=100 \mathrm{~kJ} \mathrm{~mol}^{-1}$ for presumed high barrier polymers: PET, HDPE, homo- and random PP and PEN.

The parameter $A_{p}^{\prime}$ is purportedly linked to the polymer and describes the basic diffusive properties of the polymer matrix in relation to the migrants. A high value of $A_{p}^{\prime}$ was attributed to high diffusive properties and hence high migration extent, which is the case for polyolefins. In the original publication by Begley et al. 2005, the parameter $A_{p}^{\prime}$ was determined for each polymer from diffusivity data available in literature (LDPE, HDPE and PP); or from diffusivity calculated from migration tests (PS, HIPS, PET, PEN and PA).

The actual physical meaning of $A_{p}$ and $\tau$, specially the relationship of the latter with the activation energy of diffusion; can be discussed using the information provided by the mean of the activation energy values displayed in Figure 2. This mean activation energy is $143 \mathrm{~kJ} \mathrm{~mol}^{-1}$ and corresponds, according to equation 7, to $\tau$ $=6793 \mathrm{~K}$; which is significantly different from the supposed low barrier behaviour of amorphous PS deduced from the activation energy of $E_{A}=82.3 \mathrm{~kJ} \mathrm{~mol}^{-1}$ that corresponds to the original value of $\tau=0$. In the authors opinion, this is indicative of two things: i) because of the minimal experimental data, PS was wrongly attributed a low barrier diffusion behaviour, and/or ii) $\tau$ (and by extension) $A_{p}{ }^{\prime}$ and the rest of the constants that appear in equation 1, are parameters of a multivariate model that do not seem to have any attached physical meaning, at least for the polymer that is being discussed. It is important to state that it is not the authors intention to make gratuitous remarks on the work previously done by others. The reader should bear in mind that, because of the wide range of barrier properties of the different polymers, as well as diffusing behaviour of the many different substances, the search of a general model to predict diffusion coefficients in polymers is a considerably ambitious goal that has been ongoing for several decades without a definite answer. In any case, the lack of physical meaning of the parameters does not affect the practical safety applications of the equation. 


\section{Implementation in spreadsheets}

Although the use of equation 3 does not represent a problem for any modern day computer, the fact that the equation requires the roots of the transcendental equation 4 makes it somehow impractical, especially if the preferred software is a spreadsheet. In order to simplify the prediction of migration levels, the reader can find under the DOI: 10.5281/zenodo.883073, together with the polystyrene diffusivity data sets (see section: Diffusivity data), a spreadsheet containing:

- Equation 1, together with the parameters, for the overestimation of the diffusion coefficient for each of the 4 regions.

- Equation 3 for the prediction of migration levels.

- The first 200 roots for typical values of $\alpha$, in case the user prefers to use software different from a spreadsheet for the calculations.

To this respect, the original form of equation 1 is the following:

$$
D=e^{{ }_{p}-0.1351 M^{2 / 3}+0.003 M-\frac{10454}{T}}
$$

Which, differently from equation 1 , contains only one parameter, since the original mechanistic concept states:

$$
A_{p}=A^{\prime}{ }_{p}-\tau
$$

For simplification purposes, this change of variable has already been made in equation 1 , and thus both $A_{p}{ }^{\prime}$ and $\tau$ are displayed

\section{Conclusions}

A comparison between experimental and predicted diffusivity data for amorphous PS showed that the equation that is currently recommended by the European food safety authorities for the prediction of diffusion coefficients for safety assessment of the migration levels in food, yielded unacceptable underestimated values, which was in clear contradiction with its intended safety purpose. This almost systematic underestimation was primarily due to the lack of experimental data at the time the parameters were first determined, and to a much lesser extent, to the attribution of physical meaning to the parameters this equation relies upon. Moreover, there was no available information about the degree of overestimation that could be expected from the predictions. Consequently, this equation needed an update, so it can be used for the safety purposes it was originally conceived for.

The overestimating parameters that have been calculated in this work were dimensioned for a nominal overestimation of $\times 25$ with respect to the experimental data they were derived from. With a few exceptions, the equation now yields overestimated values of diffusivity, leading to satisfactory overestimation of the migration levels, on the basis of a worst-case scenario migration test. It is important to mention that this 
equation should be used exclusively for security purposes regarding plastic materials in contact with food. Modelling of other processes based on these overestimated diffusion coefficients may lead to the process itself appearing falsely faster. Additionally, the equation, and by extension, the parameters it relies upon, do not seem to give any kind of explanation regarding the dependence of the diffusion coefficient on the molecular structure, other than an empirical link based on the experimental data.

For now, and until new diffusivity or partition data on amorphous PS is published, a reasoned use of equation 1 may help achieving the safe-by-design conception of food packaging. Further research should be performed on other polymers covered by this model in order to quantify the actual overestimating level as well as the uncertainty that can be derived from it.

\section{Acknowledgements}

This work has been possible thanks to the funding provided by the French funding agency Association Nationale de la Recherche within the framework of the Research Project SafeFoodPack Design.

\section{Bibliography}

Baner A, Brandsch J, Franz R, Piringer O. 1996. The application of a predictive migration model for evaluating the compliance of plastic materials with European food regulations ${ }^{\dagger}$. Food Addit Contam. 13:587-601.

Begley T, Biles J, Cunningham C, Piringer O. 2004. Migration of a UV stabilizer from polyethylene terephthalate (PET) into food simulants. Food Addit Contam. 21:1007-1014.

Begley T, Castle L, Feigenbaum A, Franz R, Hinrichs K, Lickly T, Mercea P, Milana M, O’Brien A, Rebre S, et al. 2005. Evaluation of migration models that might be used in support of regulations for food-contact plastics. Food Addit Contam. 22:73-90.

Bernardo G. 2012. Diffusivity of alkanes in polystyrene. J Polym Res. 19:1-9.

Bernardo G. 2013. Diffusivity of alcohols in amorphous polystyrene. J Appl Polym Sci. 127:1803-1811.

Bernardo G, Choudhury RP, Beckham HW. 2012. Diffusivity of small molecules in polymers: Carboxylic acids in polystyrene. Polymer. 53:976-983.

Crank J. 1980. The Mathematics of Diffusion. Press C, editor. [place unknown]: Oxford University Press.

Dole P, Feigenbaum A, De la Cruz C, Pastorelli S, Paseiro P, Hankemeier T, Voulzatis Y, Aucejo S, Saillard P, Papaspyrides C. 2006. Typical diffusion behaviour in packaging polymers - application to functional barriers. Food Addit Contam. 23:202-211.

Ewender J, Welle F. 2013. Determination of the activation energies of diffusion of organic molecules in poly(ethylene terephthalate). J Appl Polym Sci. 128:3885-3892.

FDA. 2002. Guidance for Industry-Preparation of Premarket Notifications for Food Contact Substances:

Chemistry Recommendation. FDA [Internet]. Available from: 
http://www.fda.gov/Food/GuidanceRegulation/GuidanceDocumentsRegulatoryInformation/Ingredient sAdditivesGRASPackaging/ucm081818.htm

Franz R, Welle F. 2008. Migration measurement and modelling from poly(ethylene terephthalate) (PET) into soft drinks and fruit juices in comparison with food simulants. Food Addit Contam Part Chem Anal Control Addit Contam Part Chem Anal Control. 25:1033-1046.

Haldimann M, Alt A, Blanc A, Brunner K, Sager F, Dudler V. 2013. Migration of antimony from PET trays into food simulant and food: determination of Arrhenius parameters and comparison of predicted and measured migration data. Food Addit Contam Part Chem Anal Control Expo Risk Assess. 30:587-598.

Hoekstra EJ, Brandsch R, Dequatre C, Mercea P, Milana M, Störmer A, Trier X, Vitrac O, Schäfer A, Simoneau C. 2015. Practical guidelines on the application of migration modelling for the estimation of specific migration. Publ Off Eur Union [Internet]. Publications Repository. Available from: http://publications.jrc.ec.europa.eu/repository/handle/JRC98028

Launay A, Thominette F, Verdu J. 1999. Water sorption in amorphous poly(ethylene terephthalate). J Appl Polym Sci. 73:1131-1137.

Martinez-Lopez B, Chalier P, Guillard V, Gontard N, Peyron S. 2014. Determination of mass transport properties in food/packaging systems by local measurement with Raman microspectroscopy. J Appl Polym Sci. 131:40958.

Martinez-Lopez B, Huguet P, Gontard N, Peyron S. 2016. Developing a Macroscopic Mechanistic Model for Low Molecular Weight Diffusion through Polymers in the Rubbery State. Ind Eng Chem Res. 55:5078-5089.

Mercea P. 2007. Models for diffusion in polymers. In: Plast Packag Mater Food [Internet]. [place unknown]: Wiley-VCH Verlag GmbH; p. 125-157. Available from: http://dx.doi.org/10.1002/9783527613281.ch05

Ogieglo W, Wormeester $\mathrm{H}$, Wessling M, Benes NE. 2013. Temperature-induced transition of the diffusion mechanism of $n$-hexane in ultra-thin polystyrene films, resolved by in-situ Spectroscopic Ellipsometry. Polymer. 54:341-348.

Pennarun P, Dole P, Feigenbaum A. 2004. Functional barriers in PET recycled bottles. Part I. Determination of diffusion coefficients in bioriented PET with and without contact with food simulants. J Appl Polym Sci. 92:2845-2858.

Pinte J, Joly C, Dole P, Feigenbaum A. 2010. Diffusion of homologous model migrants in rubbery polystyrene: molar mass dependence and activation energy of diffusion. Food Addit Contam Part Chem Anal Control Addit Contam Part Chem Anal Control. 27:557-566.

Piringer 0. 2007. Prediction of diffusion coefficients in gases, liquids, amorphous solids and plastic materials using an uniform model. In: Plast Packag Mater Food [Internet]. [place unknown]: Wiley-VCH Verlag GmbH; p. 159-181. Available from: http://dx.doi.org/10.1002/9783527613281.ch06 
Simoneau C. 2010. Applicability of generally recognised diffusion models for the estimation of specific migration in support of EU Directive 2002/72/EC. Publ Off Eur Union. Publications repository.

Tseng KC, Turro NJ, Durning CJ. 2000. Tracer diffusion in thin polystyrene films. Polymer. 41:4751-4755.

Welle F. 2012. Simulation of the Decontamination Efficiency of PET Recycling Processes based on Solid-state Polycondensation. Packag Techol Sci. Published online:n/a-n/a.

Welle F. 2013. A new method for the prediction of diffusion coefficients in PET. J Appl Polym Sci. 129:18451851.

Welle F, Franz R. 2011. Migration of antimony from PET bottles into beverages: determination of the activation energy of diffusion and migration modelling compared with literature data. Food Addit Contam Part A. 28:115-126.

Welle F, Franz R. 2012. Diffusion coefficients and activation energies of diffusion of low molecular weight migrants in Poly(ethylene terephthalate) bottles. Polym Test. 31:93-101. 


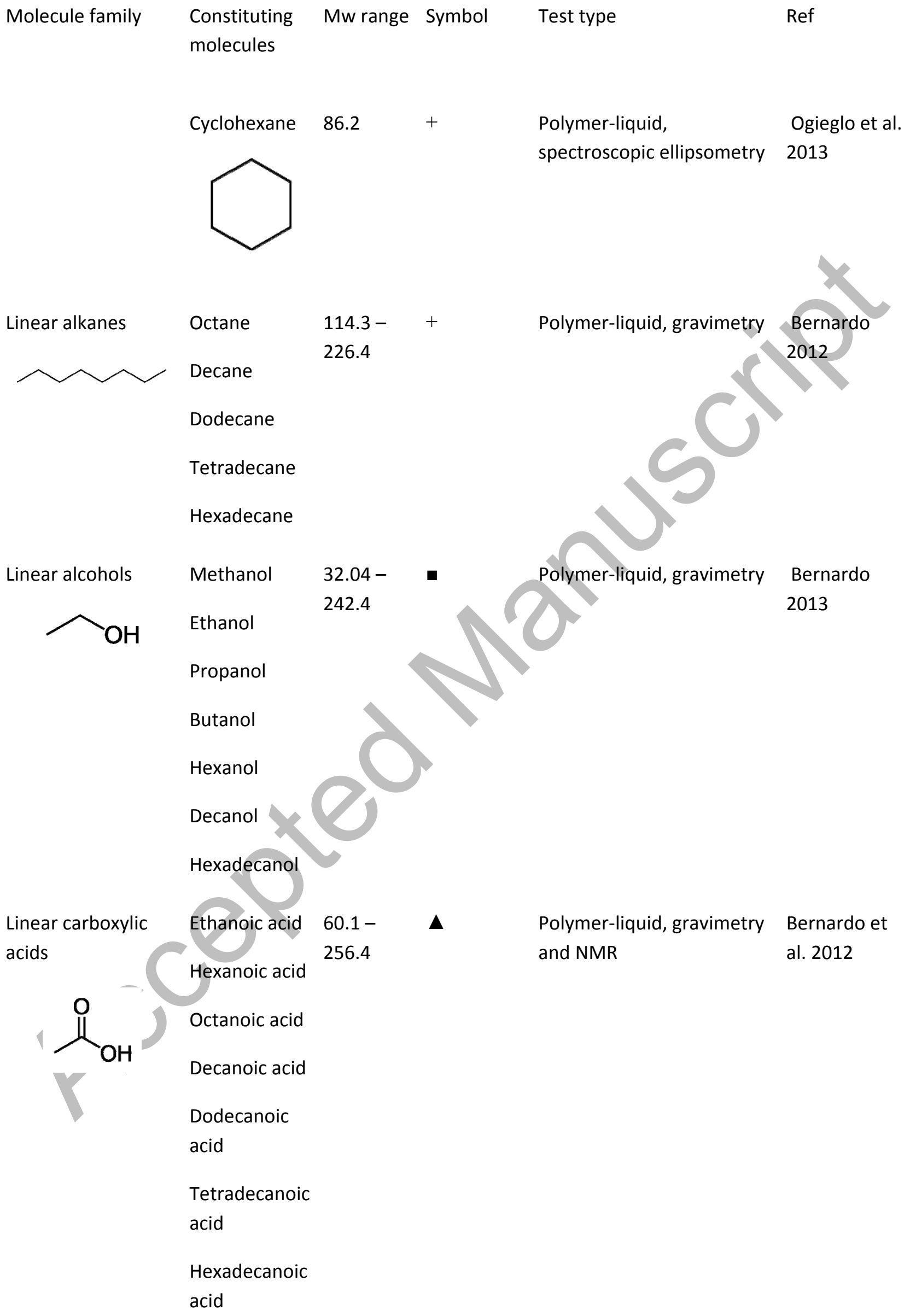


Chlorobenzen

e

Phenyl-

Cyclohexane

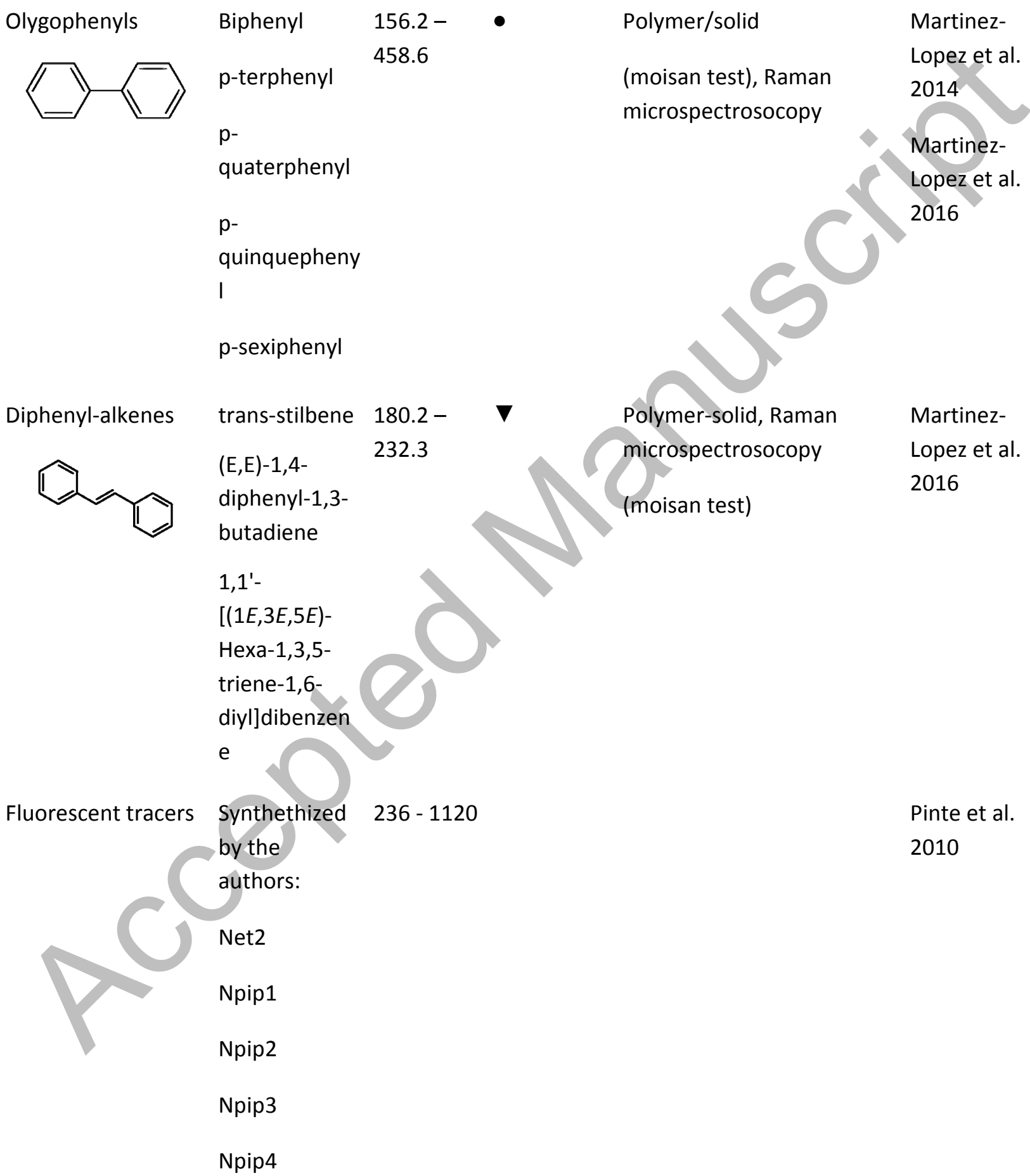




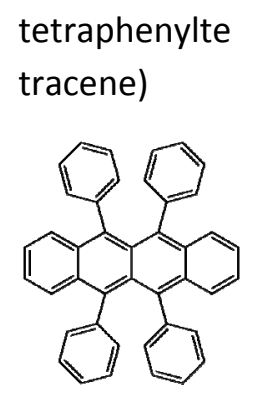

Styrene

104

Polymer/food simulant

Begley et al.

(migration test)

2005.

Table 1: Characteristics of the diffusion coefficient datasets used in this work

\begin{tabular}{|c|c|c|c|c|c|}
\hline Region & $n$ & Median D & Mean D (m & & $\tau(\mathrm{K})$ \\
\hline $\bar{a} T<T_{g}, M<230 \mathrm{~g} \cdot \mathrm{mol}^{-1}$ & 67 & $8 \times 10^{-13}$ & & 32.02 & 8778 \\
\hline $\boldsymbol{b} T>T_{g}, \mathrm{M}<230 \mathrm{~g} \cdot \mathrm{mol}^{-1}$ & 43 & $1 \times 10^{-11}$ & & 1.16 & -2584 \\
\hline$c T<T_{g}, \mathrm{M}>230 \mathrm{~g} \cdot \mathrm{mol}^{-1}$ & 14 & $3.3 \times$ & $3.3 \times 10^{-14}$ & 55.11 & 20462 \\
\hline $\boldsymbol{d} T>T_{g}, \mathrm{M}>230 \mathrm{~g} \cdot \mathrm{mol}^{-1}$ & 59 & $8.4 \times 10^{-1}$ & $1.3 \times 10^{-12}$ & 30.4 & 11240 \\
\hline
\end{tabular}

Table 2: Values of $A_{p}^{\prime}$ and $\tau$ calculated from the fit for a nominal overestimation of $\times 25$ in every region. The column $n$ designs the number of diffusivity values used for each determination.

Figure 1: Experimental diffusivity data (scatter), and predictions of equation 1 at $35,50,65,75,105,125$ and $150{ }^{\circ} \mathrm{C}$ with the original parameters found at Simoneau 2010 for PET (a) and amorphous PS (b). The colourbar represents the temperature in celsius. Table 1 displays the main characteristics of the PS datasets. 


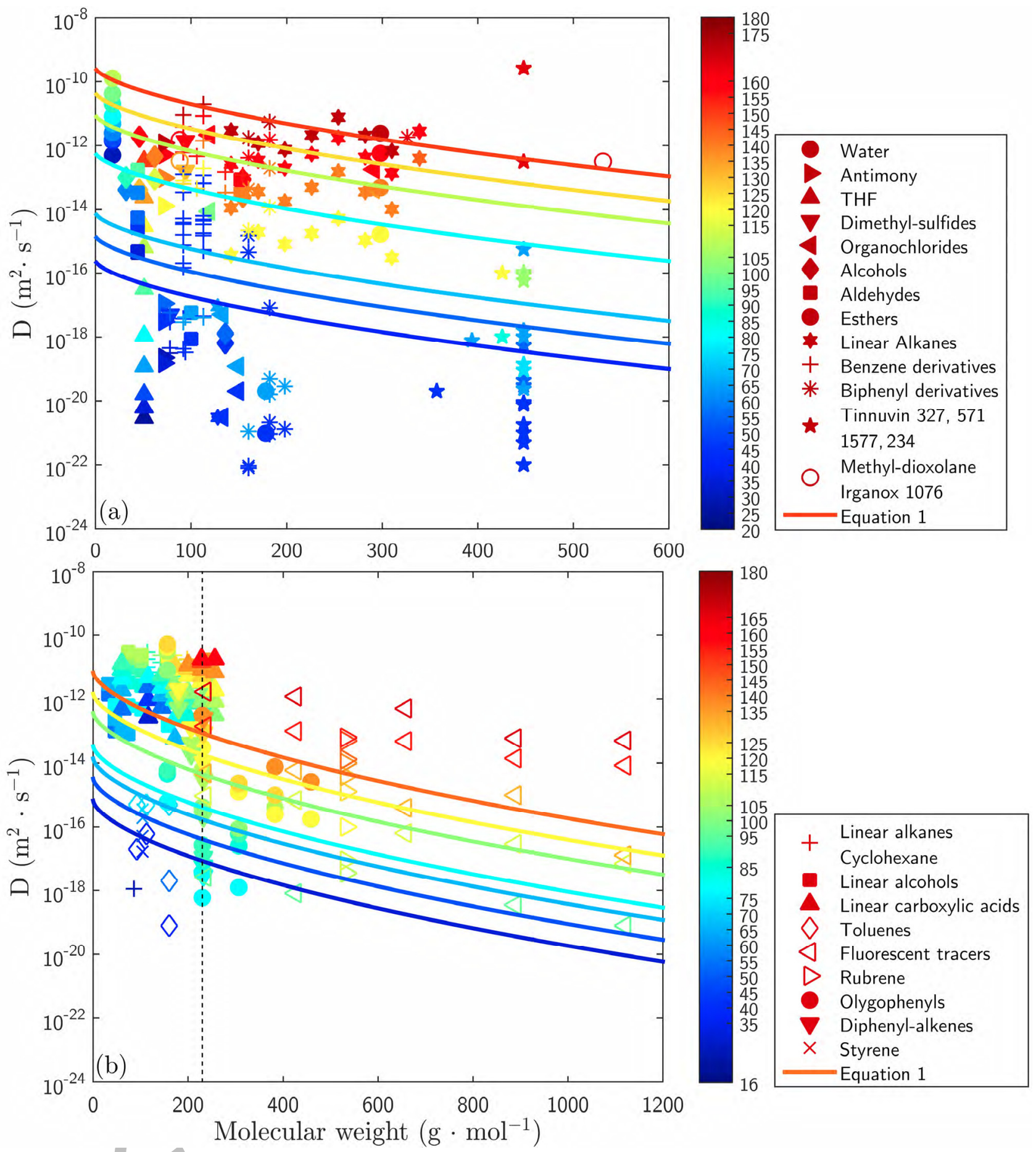

Figure 2: Activation energies of diffusion in function of the molecular weight for the molecules displayed in Figure 1. 


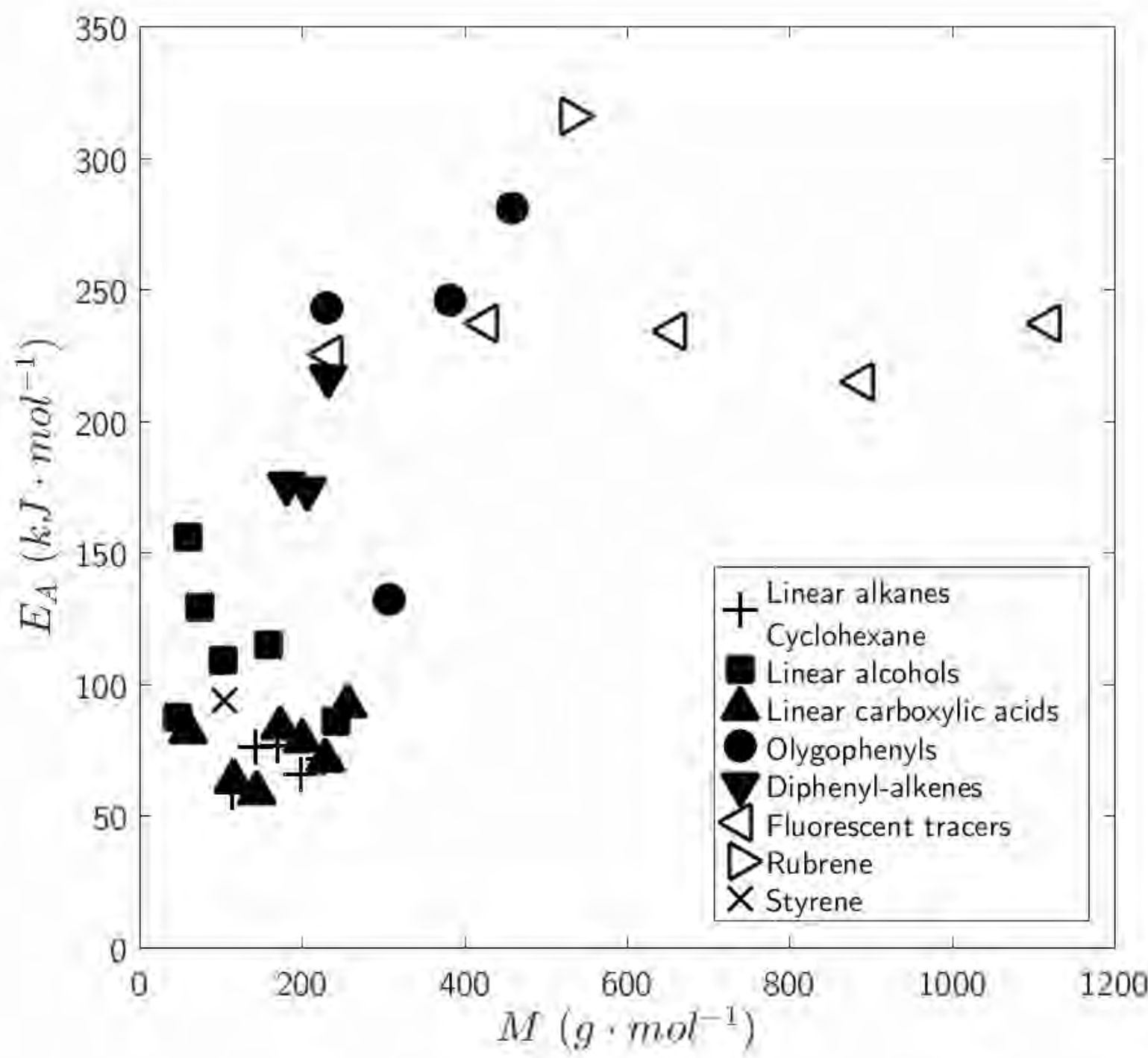

Figure 3: Evolution of the migration levels calculated with equation 3, for each of the M, T regions over 10 days, ( $=50, \mathrm{C} 0=500 \mathrm{ppm}, \mathrm{L}=300$ ?m and $6 \mathrm{dm} 2$ plastic L food-1): a) region $\mathrm{a}$ : $\mathrm{M}<230 \mathrm{~g} \mathrm{mol-1,} \mathrm{T}<\mathrm{Tg}, \mathrm{b})$ region $\mathrm{b}: \mathrm{M}<230 \mathrm{~g}$ mol-1, $\mathrm{T}>\mathrm{Tg}, \mathrm{c})$ region $\mathrm{C}: \mathrm{M}>230 \mathrm{~g} \mathrm{mol-1,} \mathrm{T}<\mathrm{Tg}$ and $\mathrm{d}$ ) region $\mathrm{d} \mathrm{M}>230 \mathrm{gmol}-1$, $\mathrm{T}>\mathrm{Tg}$. Migration levels were calculated for three different diffusivity values: the median of the diffusivities of each region (black line), the median of the multiplied by a 10 factor (dark brown) and the median of the region multiplied by a factor 25 (light brown). 

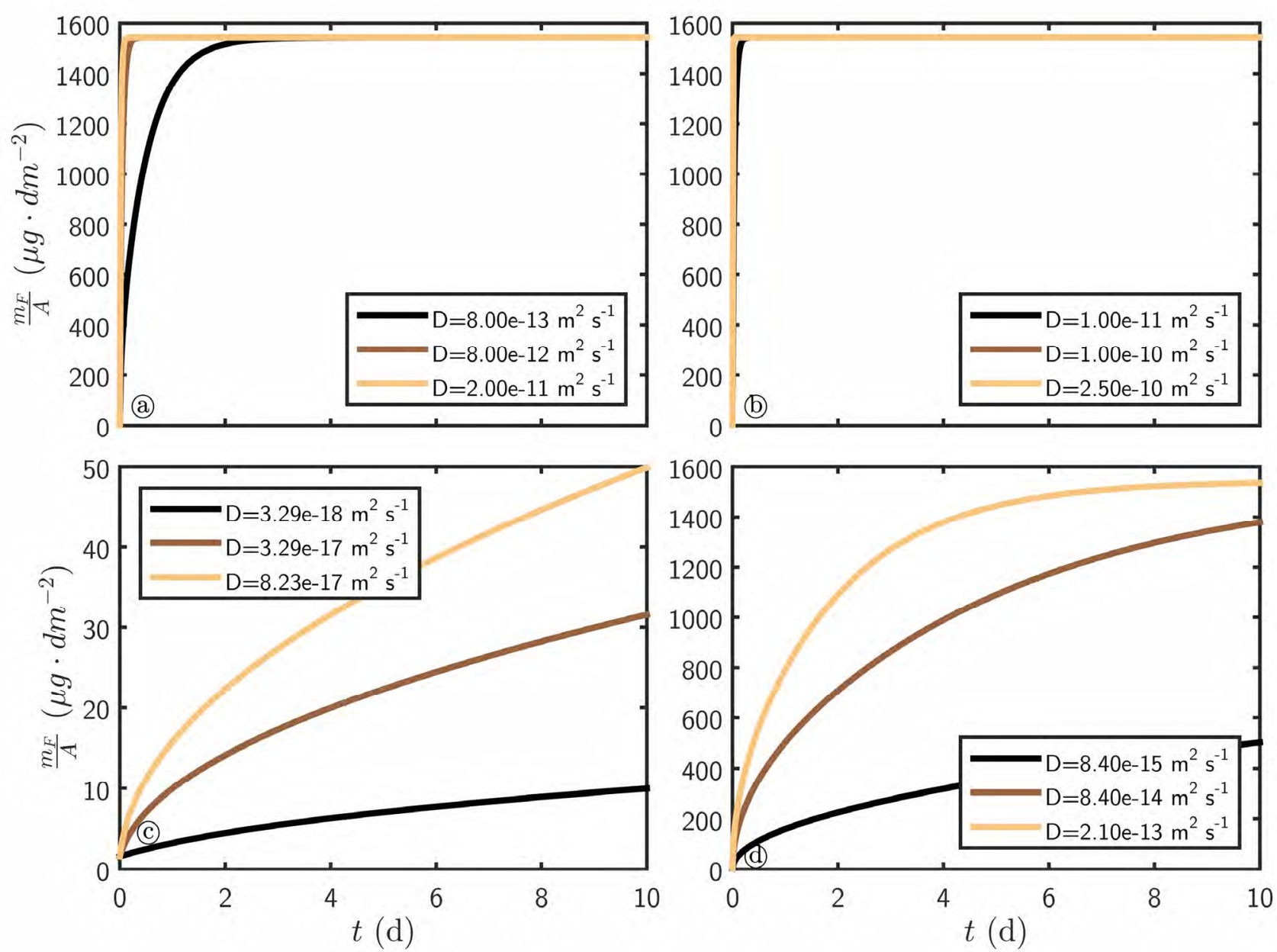

Figure 4: plot of literature diffusivity data for PS (scatter) and prediction from equation (1) by using the parameters shown in Table 2, which have been determined for a nominal overestimation of $\times 25$. Symbols represent the same molecule families as in figure $1 \mathrm{~b}$. 


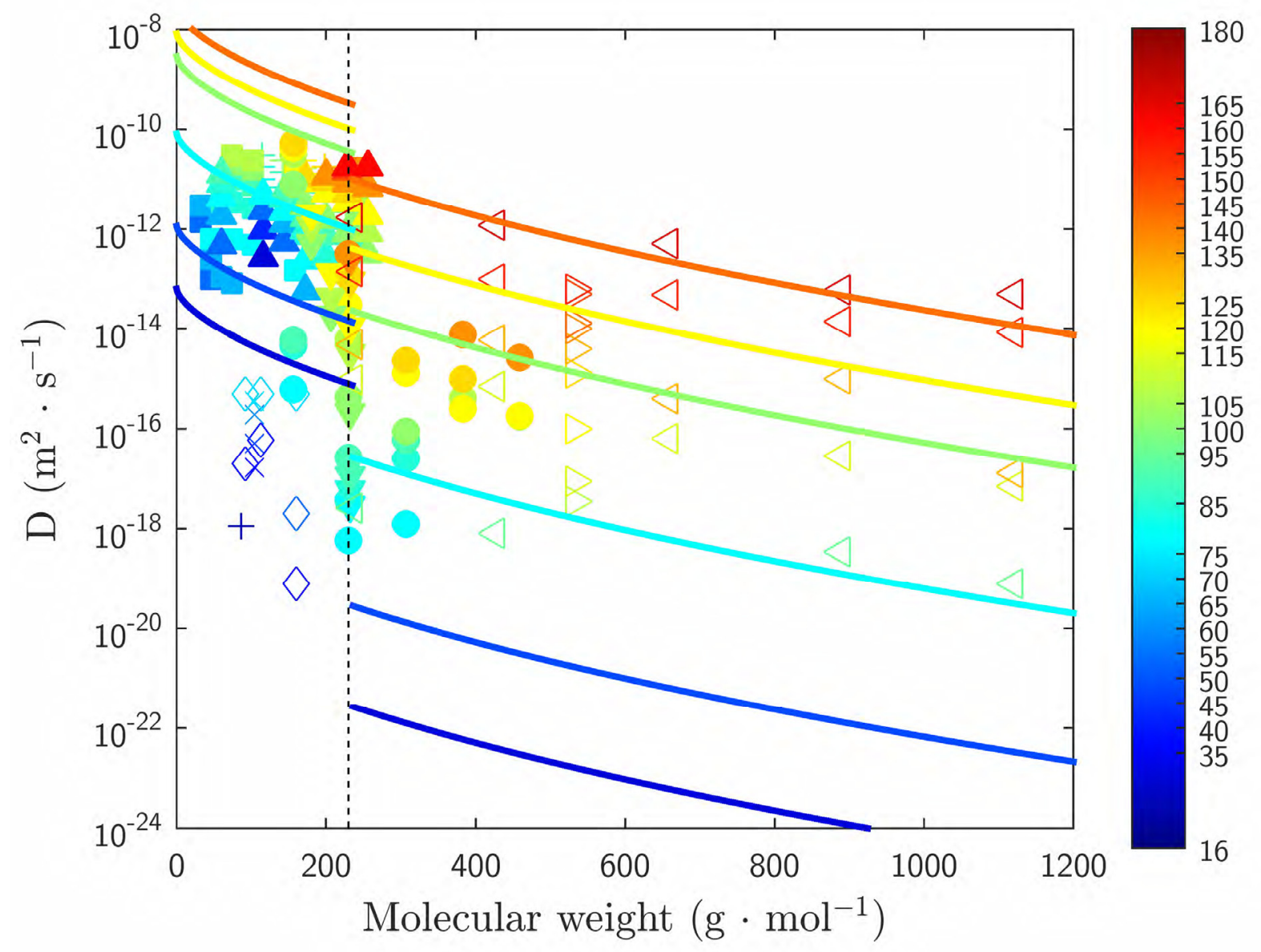

Figure 5: Prediction of migration levels ?g dm-2 after 10 days and ?=50, by using equation 2 with the experimental data gathered for amorphous PS (scatter), as well as the diffusivity values predicted by equation 1 with the original parameters found at Hoekstra et al. 2015 (a), and the parameters found for a nominal overestimation of the diffusion coefficient of $\times 25$, that can be found in Table 2 (b). Symbols represent the same molecule families as in figure 1 b.
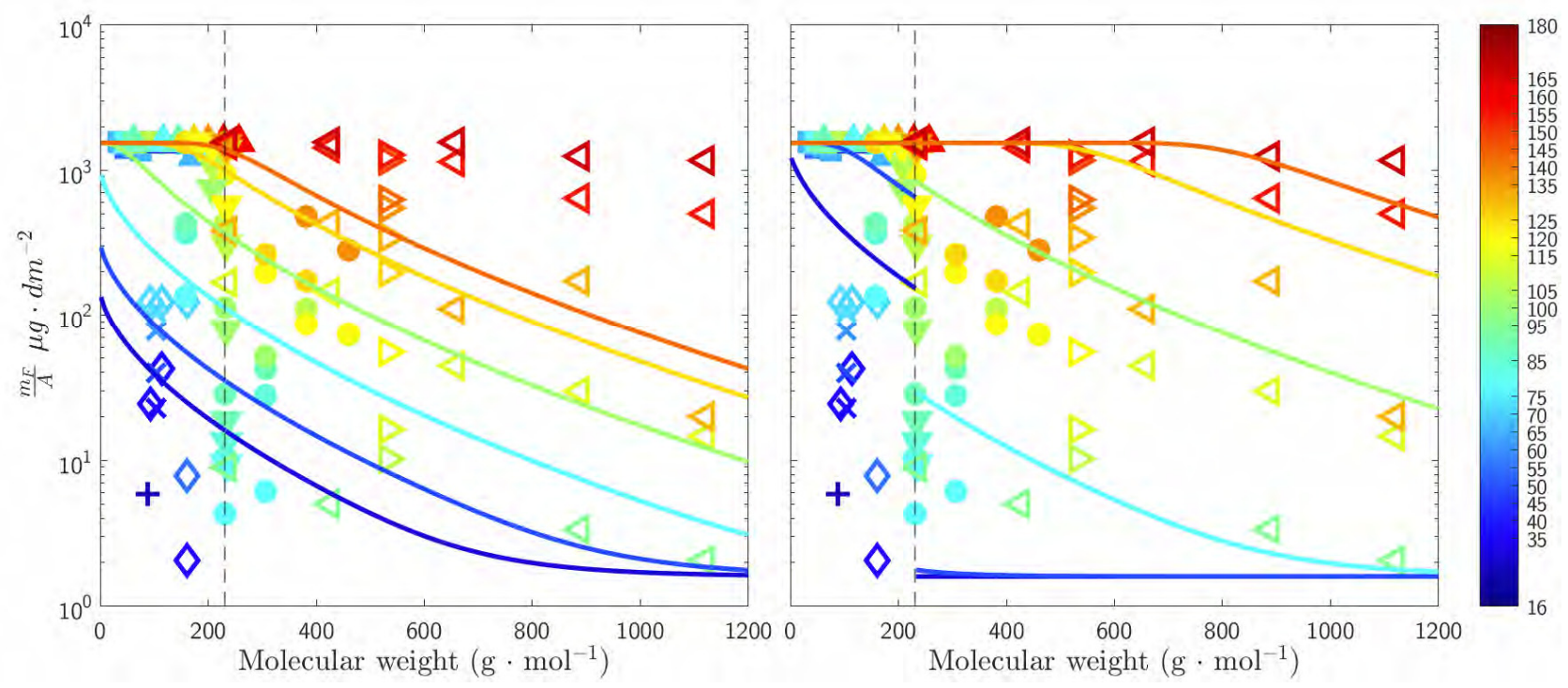

Figure 6: Overestimation of migration levels computed with equation 1 after 10 days, calculated as the ratio between the migration levels resulting from the use the diffusivity data predicted by equation 1 (MF,pred) and the experimental diffusivity data found in literature (MF,exp). (a) original parameters and ? $=0.05$, (b) 
parameters from Table 1 and $?=0.05$, (c) original parameters and $?=50$, (d) parameters from Table 1 and $?=50$.
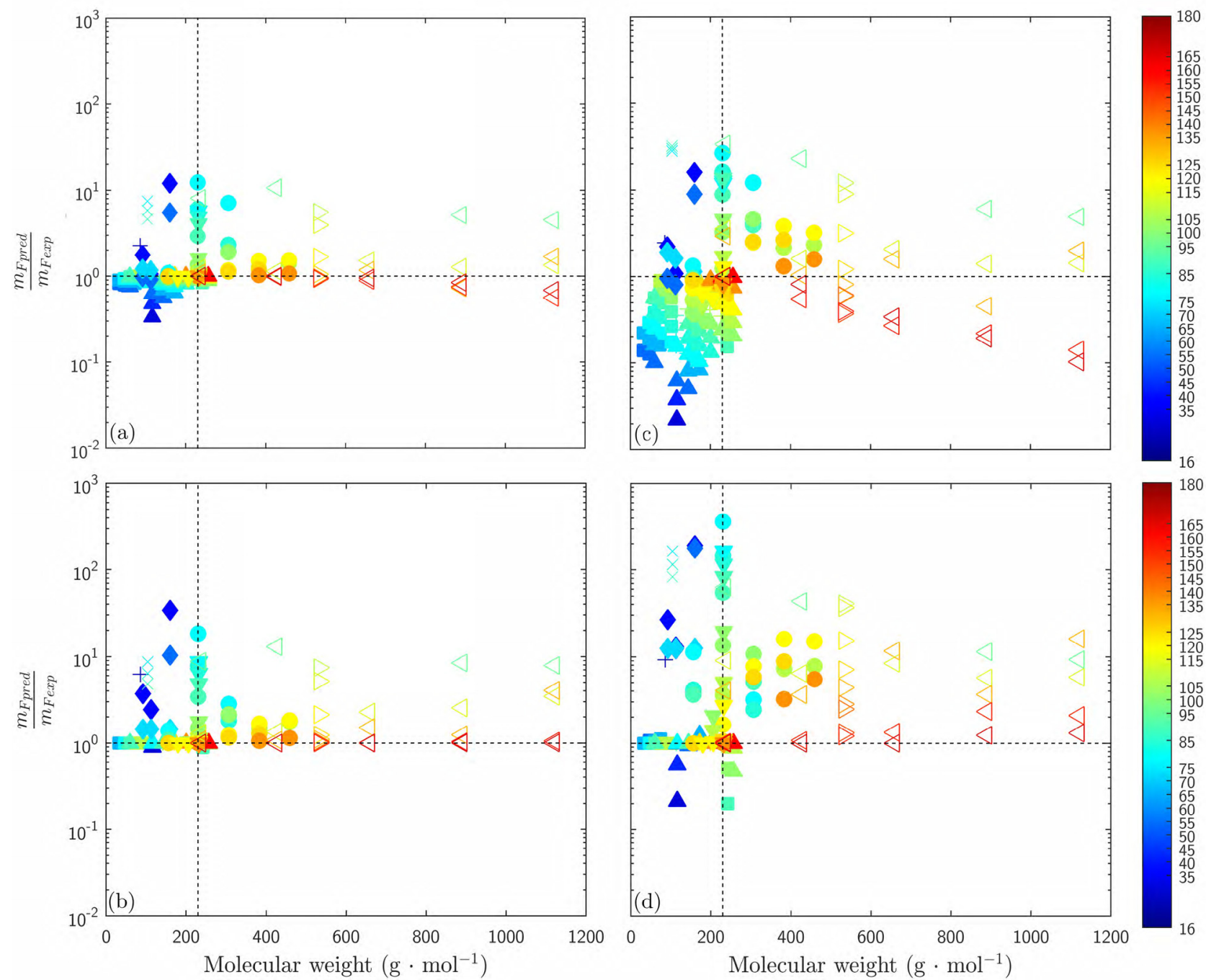